\title{
A Calibration Technique for Bi-axial Shake Tables with Stepper Motor
}

\author{
Erdem DAMCI ${ }^{1}$ \\ Çağla ŞEKERCI ${ }^{2}$ \\ Yener TAŞKIN ${ }^{3}$ \\ Koray GÜRKAN ${ }^{4}$
}

\begin{abstract}
Shaking tables are frequently used to determine the dynamic behavior of structures in the laboratory environment. In order to obtain realistic results in experimental studies, table response and performance should be consistent with the desired motion. In this multidisciplinary study, an application of a new method for determining and calibrating the mechanical response of a developed bi-axial displacement controlled shake table according to the desired motion data is presented. The bi-axial shake table's electro-mechanical components consist of stepper motors, ball screw sets, linear ball bearings, and linear potentiometers positioned on both axes for displacement measurements. For the control and data acquisition (DAQ) unit of the shake table, an open-source electronic prototyping platform Arduino was used. From several experimental results, it was seen that, with the presented calibration method, harmonic and earthquake simulations could be achieved with a relative root mean square error (relative RMS error) of less than 5\% for desired displacement-time histories.
\end{abstract}

Keywords: Shaking table, calibration, Arduino, stepper motor, ball screw set, linear ball bearing, linear potentiometer.

Note:

- This paper was received on October 18, 2019 and accepted for publication by the Editorial Board on September 18, 2020.

- Discussions on this paper will be accepted by May 31, 2022.

- https://doi.org/10.18400/tekderg.634582

1 Istanbul University - Cerrahpasa, Department of Civil Engineering, Istanbul, Turkey edamci@iuc.edu.tr - https://orcid.org/0000-0003-2295-1686

2 Dogus University, Department of Civil Engineering, Istanbul, Turkey csekerci@dogus.edu.tr - https://orcid.org/0000-0001-7070-1804

3 Istanbul University - Cerrahpasa, Department of Mechanical Engineering, Istanbul, Turkey ytaskin@iuc.edu.tr - https://orcid.org/0000-0003-1923-2672

4 Istanbul University - Cerrahpasa, Department of Electrical \& Electronics Engineering, Istanbul, Turkey kgurkan@iuc.edu.tr - https://orcid.org/0000-0003-2283-8173 


\section{INTRODUCTION}

In the field of civil engineering, the dynamic effects such as earthquakes on buildings are among the foremost research topics. The number of laboratories capable of conducting experiments by simulating earthquake records on real structures is limited worldwide and it requires high investment budgets to examine the effects of earthquakes on structures. However, shake tables are widely used to investigate dynamic behaviors through smaller scale models and smaller loading areas. On such shaking tables using scaled structure models, records from earthquakes or synthetically produced earthquake signals can be simulated as $1 / 1$ or scaled, and many academic studies examining the effects of these earthquakes on buildings exist in the literature [1, 2]. However, shaking tables are often used to verify or compare numerical analyses on complex or simplified structures under harmonic loading and earthquake loading. The accuracy of the table performance and the monitoring system is also essential, in addition to the fact that the model to be placed on the shake table should be compatible with the numerical analysis model. Therefore, in experimental studies, the table response and the target motion should be in harmony to ensure that the results are as close to reality as possible. For this purpose, before the experimental studies on the structural model, the demand-response relationship should be determined, and the calibration of the shake table to be used should be checked or performed if required.

In this context, there are many studies in the literature aimed at improving table performance. Kuehn et al. [3] developed a computer-based control system to improve the data acquisition characteristics of a small shaking table and showed that the data obtained by monitoring the system and the desired seismic motion were the same. Nakata [4], on the other hand, mentioned a monitoring system that would provide acceleration control and system stability by using a feedback system and confirmed its reproducibility with experiments on a single axis shaking table. Luco et al. [5] studied the performance of the acceleration tracking of a uniaxial shaking table and proposed improvements to the instrument by performing harmonic scanning for different amplitudes and frequencies. Yang et al. [6], in their study on the acceleration, velocity, and displacement control of a high-performance shaking table to investigate nonlinear behavior in the system. In addition to the studies on increasing the performance of the table and monitoring system, there are also studies examining small scale models placed on shaking tables. Saranik et al. [7] examined non-elastic behavior and changes in modal parameters of a two-layer steel frame with bolted joints under dynamic effects and compared them with numerical analysis results. Zhang et al. [8] compared the numerical of a shear frame by performing a shaking table and real-time hybrid simulation. Altunışık et al. [9] determined the dynamic characteristics and dynamic behavior of the shaking table experiments by forming a model containing a calibrated liquid column damper. Alemdar [10] compared the deformation results obtained by both shaking table experiments and finite element analyses under bi-axial earthquake loads of reinforced concrete bridge columns and examined the plastic deformations. Ashasi-Sorkhabi et al. [11] investigated the accuracy of a Quanser shake table with real-time hybrid simulation using the response from a spring-mass oscillator and tuned liquid damper system. Najafi and Spencer [12] developed the modified model-based controllers' method in their studies, and with this method, they investigated the accuracy of a single-axis Quanser shake table and determined the error rates with different methods and compared the methods. Damc1 and Şekerci [13] developed a single axis, $500 \times 500 \mathrm{~mm}^{2}$ shake table controlled by Arduino microcontroller platforms and 
driven by a stepper motor. The control algorithm, calibration method, and performance investigation of the shake table were given in detail.

In this study, an application of the calibration method given by Damc1 and Şekerci [13] is introduced for the new bi-axial shake table SARSAR (Figure 1), which is placed in Structures and Mechanics Laboratory at Istanbul University-Cerrahpasa in Buyukcekmece campus, is presented. There are considerable differences compared to the previous study [13]. This study is a further application of the method for a larger bi-axial shake table with higher payloads up to $600 \mathrm{~kg}$. The main contribution is to apply and validate the calibration method to a biaxial shake table which is an open-loop displacement controlled earthquake and harmonic motion simulator, developed within the scope of a TUBITAK project. Apart from the number of axes used in both shake tables, the dimensions and capacities are also different from each other. Operational payload and bandwidth have in particular been improved in the present study. It was shown that the method could be used for larger shake tables with different electro-mechanical configurations. Numerous experimental investigations are carried out for the calibration process and its validation with the help of relative root mean square error (relative RMS error) calculations and newly-added synchronization subspace plots (SSP) to find the shake table's frequency response and earthquake simulation performance. Also, comparisons of desired and achieved frequency contents and acceleration response spectra are given for the demonstration of earthquake performance. From an engineering perspective in civil engineering, it was shown that the shake table's performance is at the desired level with a relative RMS error of about $5 \%$.

\section{MATERIALS ANS METHODS}

\subsection{Specifications of Developed Shaking Table}

In the developed bi-axial shaking table, the ability to move along each axis is obtained by forming two planes arranged on top of each other such that each axis forms a plane. The lower plane $x$, upper plane constitutes the movement in the $y$-axis shown in Figure 1. The top plane with a loading area has a dimension of $1000 \mathrm{~mm} \times 1000 \mathrm{~mm}$ and moves in the $y$-axis. The center plate on which this plane sits is $1000 \mathrm{~mm} \times 1100 \mathrm{~mm}$ and provides movement in the $x$-axis. The table dimensions that consist of the fixed bottom plane are $1000 \mathrm{~mm} \times 1300$ $\mathrm{mm}$. Both axes have a displacement capability of $\pm 150 \mathrm{~mm}$. A total of 4 limit switches are installed to ensure the table's safety against the possibility of exceeding the maximum displacement limits in the $x$ and $y$ directions. The table movement is automatically stopped when any limit switch is opened. Linear motion on both axes is provided by actuators consisting of a stepper motor with a capacity of 12 N.m and a 2020 precision ball screw with a pitch of $20 \mathrm{~mm}$. The 2-phase hybrid stepper motors, which complete one turn in 200 steps, are controlled by digital drivers that can provide continuous high current. The digital drivers are set to 400 steps/revolution to increase motion resolution. Therefore, the motion resolution of the shake table on each axis corresponds to $\Delta s=20 / 400=0.05 \mathrm{~mm}$. The general view of the table is given in Figure 1. The technical specifications of the shake table developed within the scope of this and preceding [13] studies are summarized in Table 1. 


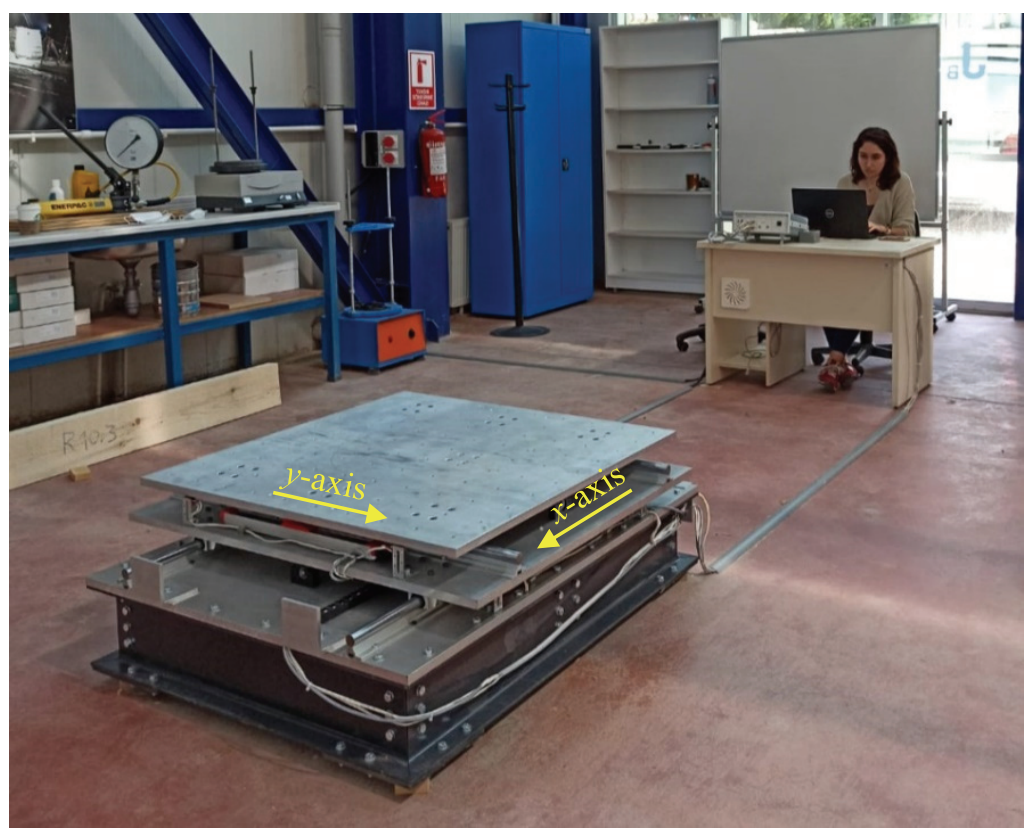

Figure 1 - Bi-axial shake table SARSAR

Table 1 - Technical specifications of the shake tables for present and previous [13] studies

\begin{tabular}{lll} 
& Present Study & Previous Study [13] \\
\hline Parameter & Value & Value \\
\hline Degrees of freedom & Two & One \\
Moving top plate dimensions ( $y$-axis) & $1000 \times 1000 \mathrm{~mm}^{2}$ & $500 \times 500 \mathrm{~mm}^{2}$ \\
Operational payload & $500 \mathrm{~kg}$ & $200 \mathrm{~kg}$ \\
Maximum motor torque & $12 \mathrm{~N} . \mathrm{m}$ & $8.5 \mathrm{~N} . \mathrm{m}$ \\
Stroke & $\pm 150 \mathrm{~mm}$ & $\pm 75 \mathrm{~mm}$ \\
Motion resolution & $50 \mu \mathrm{m} / \mathrm{step}$ & $25 \mu \mathrm{m} / \mathrm{step}$ \\
Peak velocity & $700 \mathrm{~mm} / \mathrm{s}$ & $350 \mathrm{~mm} / \mathrm{s}$ \\
& $1.35 \mathrm{~g} @ \pm 1 \mathrm{~mm}$ in $x$ - & \\
Peak acceleration (bare table) & axis & $1.5 \mathrm{~g} @ \pm 1 \mathrm{~mm}$ \\
& $1.95 \mathrm{~g} @ \pm 1 \mathrm{~mm}$ in $y$ - & \\
& axis & \\
Peak acceleration (600 kg payload) & $0.28 \mathrm{~g} @ \pm 1 \mathrm{~mm}$ in $x$ - & - \\
& axis & $0.30 \mathrm{~g} @ \pm 1 \mathrm{~mm}$ in $y$ - \\
Operational bandwidth & axis & \\
Self-weight & $30 \mathrm{~Hz}$ & $17 \mathrm{~Hz}$ \\
\hline
\end{tabular}


The control and data acquisition unit of the shake table consists of commercialoff-the-shelf Arduino development boards. The motion signal to be sent to the stepper motor drivers is realized using two Arduino DUE boards. Each board uses a 32-bit ARM-Cortex processor with a clock speed of $84 \mathrm{MHz}$ and $512 \mathrm{~KB}$ flash memory. An Arduino MEGA development board is also used to measure the response of the table to the sent motion signal. It is a development board with an 8-bit ATMEGA256 flash microcontroller running at $16 \mathrm{MHz}$ with a $256 \mathrm{~KB}$ flash memory. The displacement of the table on both axes is measured using two linear potentiometers with a $350 \mathrm{~mm}$ stroke, which were placed between the moving plates of the table. Analog signals of the potentiometers digitized by Arduino MEGA's analog-to-digital-converter (ADC) with 10-bit resolution and converted to the corresponding displacement.

\subsection{Method for Calibrating the Shaking Table}

Bi-axial harmonic motion and strong ground motion can be simulated with the shaking table. In order to obtain the correct response of the scaled model placed on the table, the simulated motion must be performed with minimum error. For this purpose, in harmonic motion, frequency scanning was performed for different amplitudes, and the desired amplitude and frequencies were compared with the measured amplitude and frequencies. The dominant frequency was determined by calculating the power spectrum of the measured displacement signal, and the shake table was calibrated via the difference between the desired frequencies. The difference between these frequencies, representing the total delay for a single cycle, can be obtained by Eq. (1). The latency corresponds to a single step for the desired motion and is calculated by dividing the number of steps required for a period of harmonic motion using this obtained delay. Where $f_{d}$ represents the desired (demand) frequency, $f_{a}$ is the achieved (response) frequency, and $A$ represents the amplitude of the harmonic motion, and $l t c_{f}$ represents the calculated latency per step [13].

$$
l t c_{f}=\left(\frac{1}{f_{a}}-\frac{1}{f_{d}}\right) \times \frac{\Delta s}{4 A}
$$

Control signals to drive the shake table were calibrated according to the latency values obtained by Equation (1) and were replaced in the controlling software and using the displacement recordings. The table response was rechecked with Eq. (1) to ensure that the calibration process is successful [13].

\section{RESULTS}

\subsection{Calibration under Harmonic Motion}

Calibration of the table is provided with the latency values obtained as a result of harmonic scanning for different amplitudes and frequencies with the help of the Equation (1) for each axis individually. Displacement-time data measured from potentiometers on the table using the data acquisition unit were used to determine the delay values. In order to determine the difference between the demand signal and the response signal and obtain the latency values, 
the demand and response frequencies were evaluated by calculating the power spectra using a code developed in Matlab environment [14]. The similarity of the two signals was also analyzed by the cross-correlation method.

Latency values obtained for various frequency-amplitude responses by numerous experimental studies conducted in this way are given in Table 2 and Table 3 for $x$ and $y$ axes, respectively. The main reasons for the differences in latency values observed on each axis are caused by small variations of the electro-mechanical parameters of the system, such as motor coil resistance and inductance, flux density of permanent magnets of the motor, switching behavior of Arduino boards and micro-stepping drivers. The (-) sign for upper frequencies in Table 2 indicates that the table payload limits are exceeded and cannot achieve these frequencies due to the mass of the bare table's moving parts placed on the $x$-axis. Although the table can reach high frequencies at low amplitudes $(22 \mathrm{~Hz} @ \pm 1 \mathrm{~mm})$, the maximum frequency at large amplitudes can be $1 \mathrm{~Hz}$. For intermediate values not given in Table 2 and Table 3, linear interpolation can be used to calculate latency values. The frequency responses of the bare table at 0.5 and $0.75 \mathrm{~Hz}$ for the maximum displacement \pm 150 $\mathrm{mm}$ on the $y$-axis are given in Figures 2 and 3, respectively. For example, for the experiments carried out under load, a mass of $600 \mathrm{~kg}$ is placed on the table (Figure 4), and the target frequency is taken as $0.53 \mathrm{~Hz}$. In Table 3 , the linear interpolation between the values given for $7.37 \mu \mathrm{s}$ at $0.5 \mathrm{~Hz}$ and $7.21 \mu \mathrm{s}$ at $0.75 \mathrm{~Hz}$ for $150 \mathrm{~mm}$ was calculated, and the delay value was obtained as $7.35 \mu \mathrm{s}$. The recording with the motion signal generated using this latency value is given in Figure 5. The table response to the demand frequency of $0.53 \mathrm{~Hz}$ was calculated as 0.53036 . As can be seen, the difference is $0.07 \%$, and the delay is calculated as $-106 \mathrm{~ns}$ after calibration.

Table 2 - Latencies at different frequency and amplitudes for calibration of $x$-axis ( $\mu$ s)

\begin{tabular}{|c|c|c|c|c|c|c|c|c|c|c|c|c|c|c|c|c|}
\hline & & & & & & & Ampl & tude [ & $\mathbf{m m}]($ & -axis) & & & & & & \\
\hline & 5 & 10 & 20 & 30 & 40 & 50 & 60 & 70 & 80 & 90 & 100 & 110 & 120 & 130 & 140 & 150 \\
\hline 0.5 & 6.67 & 8.21 & 7.86 & 7.58 & 7.59 & 7.60 & 7.86 & 7.42 & 7.28 & 7.28 & 7.42 & 7.77 & 7.26 & 7.24 & 7.24 & 7.36 \\
\hline 0.75 & 7.14 & 7.74 & 7.62 & 7.31 & 7.50 & 7.50 & 7.42 & 7.77 & 7.78 & 7.74 & 7.19 & 7.73 & 7.20 & 7.37 & 7.20 & 7.21 \\
\hline 1 & 6.67 & 7.14 & 7.50 & 7.78 & 7.41 & 7.74 & 7.18 & 7.21 & 7.22 & 7.33 & 7.23 & - & - & - & - & - \\
\hline 1.5 & 6.19 & 6.68 & 7.22 & 7.30 & 7.23 & 7.33 & 7.36 & 7.19 & - & - & - & & & & & \\
\hline 2 & 6.90 & 6.85 & 7.28 & 7.22 & 7.21 & - & - & - & & & & & & & & \\
\hline 2.5 & 6.43 & 6.80 & 7.20 & 7.26 & - & & & & & & & & & & & \\
\hline 3 & 6.97 & 7.38 & 7.62 & - & & & & & & & & & & & & \\
\hline 4 & 7.14 & 7.02 & - & & & & & & & & & & & & & \\
\hline 5 & 6.67 & 7.62 & & & & & & & & & & & & & & \\
\hline 6 & 7.46 & - & & & & & & & & & & & & & & \\
\hline 7 & 7.35 & & & & & & & & & & & & & & & \\
\hline 8 & - & & & & & & & & & & & & & & & \\
\hline
\end{tabular}

The same process for the specified frequency at $150 \mathrm{~mm}$ amplitude of $0.53 \mathrm{~Hz}$ is calculated via Table 3 for the desired latency value, where $7.82 \mu$ s for $0.5 \mathrm{~Hz}$ and $7.75 \mu$ s latency for $0.75 \mathrm{~Hz}$ were given for $110 \mathrm{~mm}$ amplitude. Linear interpolation was performed using these values, and the delay value was obtained as $7.78 \mu \mathrm{s}$ for $0.65 \mathrm{~Hz}$. As a result of the 
measurements taken by the calibration process, the table response for the target/demand frequency of $0.65 \mathrm{~Hz}$ was obtained $0.65003 \mathrm{~Hz}$. The difference between demand and response frequencies was found to be $0.005 \%$. Therefore, the latency of calibrated harmonic motion was determined as $-9.16 \mathrm{~ns}$, as shown in Figure 6. The displacement error in the time domain for achieved vs. desired harmonic motions are shown in Figure 7 for un-calibrated and calibrated cases using synchronization subspace plots (SSP). In Figure 7a, the effect of cumulative latency, which increases the magnitude of total delay, can be seen clearly. Using the appropriate latency value for calibrating the motion signal data, the effect of cumulative latency that causes the total delay was minimized, where the synchronization plot in Figure $7 \mathrm{~b}$, nearly shows an overlapped position compared to ideal SSP line which has a slope of $45^{\circ}$.

Table 3 - Latencies at different frequency and amplitudes for calibration of y-axis ( $\mu$ s)

\begin{tabular}{|c|c|c|c|c|c|c|c|c|c|c|c|c|c|c|c|c|}
\hline & \multicolumn{16}{|c|}{ Amplitude [mm] (y-axis) } \\
\hline & 5 & 10 & 20 & 30 & 40 & 50 & 60 & 70 & 80 & 90 & 100 & 110 & 120 & 130 & 140 & 150 \\
\hline 0.5 & 8.81 & 8.57 & 8.15 & 7.86 & 7.59 & 7.69 & 8.00 & 7.50 & 7.35 & 7.30 & 7.45 & 7.82 & 7.31 & 7.27 & 7.26 & 7.37 \\
\hline 0.75 & 8.33 & 8.57 & 7.86 & 7.51 & 7.56 & 7.45 & 7.46 & 7.82 & 7.81 & 7.77 & 7.21 & 7.75 & 7.20 & 7.37 & 7.20 & 7.21 \\
\hline 1 & 7.14 & 7.98 & 7.62 & 7.90 & 7.41 & 7.79 & 7.28 & 7.25 & 7.22 & 7.33 & 7.23 & 7.18 & 7.19 & 9.06 & 7.34 & 7.32 \\
\hline 1.5 & 9.05 & 7.29 & 7.46 & 7.38 & 7.23 & 7.33 & 7.40 & 7.19 & 7.35 & 7.32 & 7.31 & & & & & \\
\hline 2 & 8.33 & 7.58 & 7.40 & 7.22 & 7.21 & 7.41 & 9.28 & 7.30 & & & & & & & & \\
\hline 2.5 & 7.86 & 7.28 & 7.32 & 7.26 & 7.35 & & & & & & & & & & & \\
\hline 3 & 7.45 & 7.62 & 7.62 & 7.30 & & & & & & & & & & & & \\
\hline 4 & 7.14 & 7.26 & 7.68 & & & & & & & & & & & & & \\
\hline 5 & 8.10 & 7.86 & & & & & & & & & & & & & & \\
\hline 6 & 7.46 & 7.26 & & & & & & & & & & & & & & \\
\hline 7 & 7.35 & & & & & & & & & & & & & & & \\
\hline 8 & 6.85 & & & & & & & & & & & & & & & \\
\hline 9 & 7.06 & & & & & & & & & & & & & & & \\
\hline
\end{tabular}
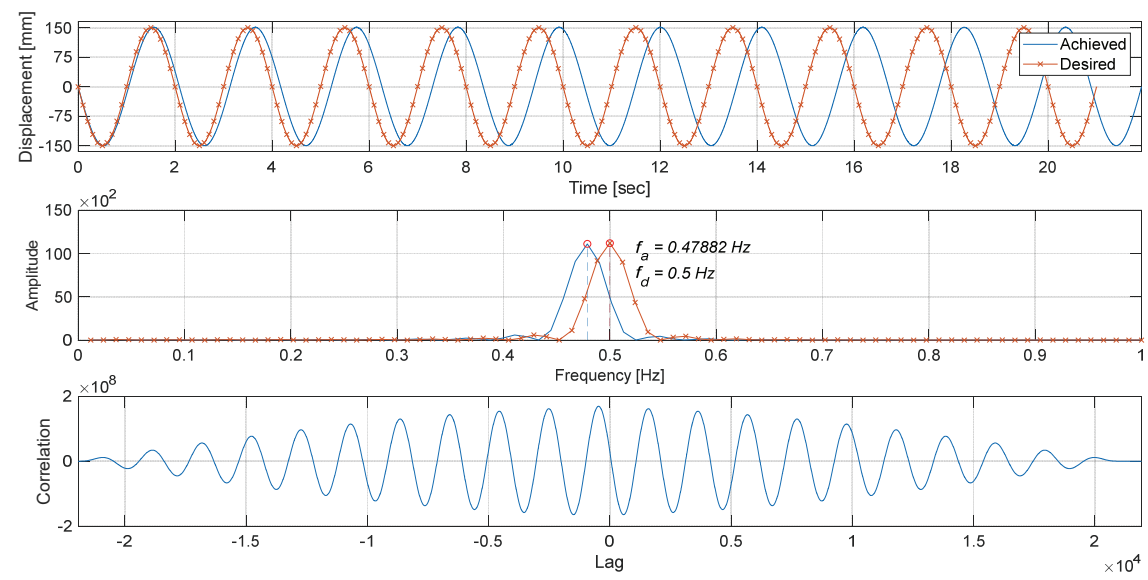

Figure 2 - Un-calibrated results for $150 \mathrm{~mm}$ amplitude at $0.5 \mathrm{~Hz}$ for the bare table 

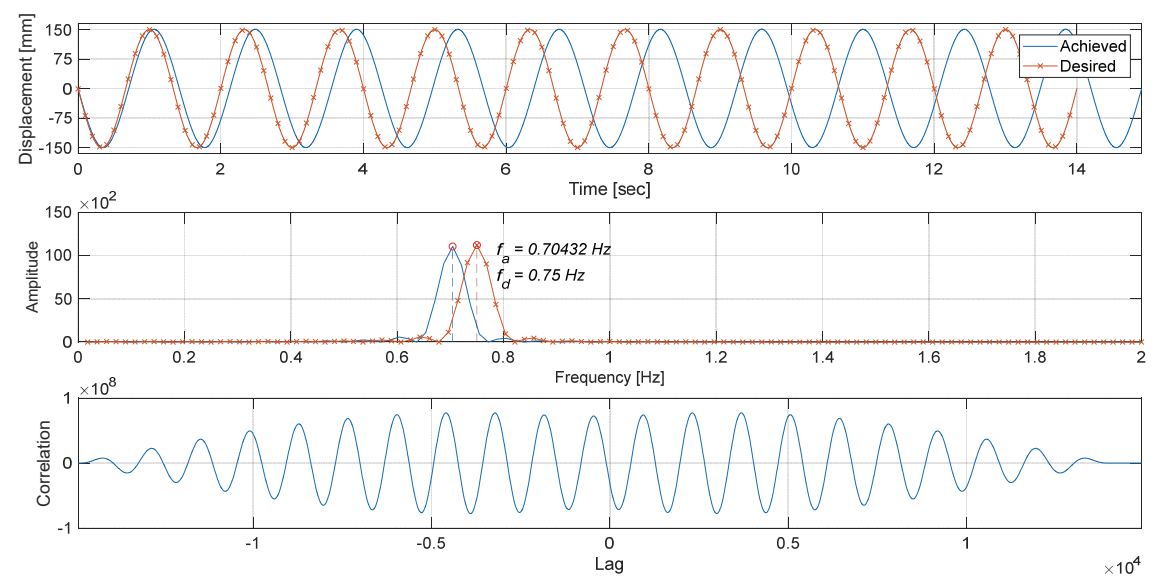

Figure 3 - Un-calibrated results for $150 \mathrm{~mm}$ amplitude at $0.75 \mathrm{~Hz}$ for the bare table

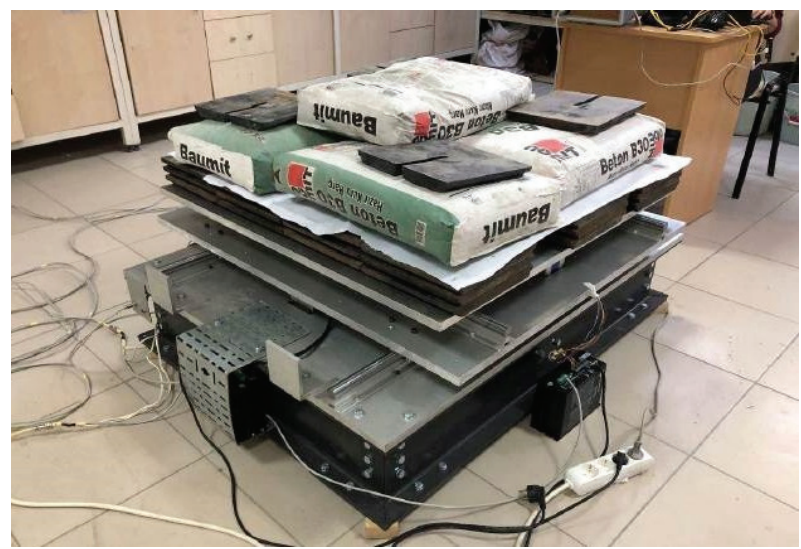

Figure 4 - A photo from the tests performed under $600 \mathrm{~kg}$ lumped mass
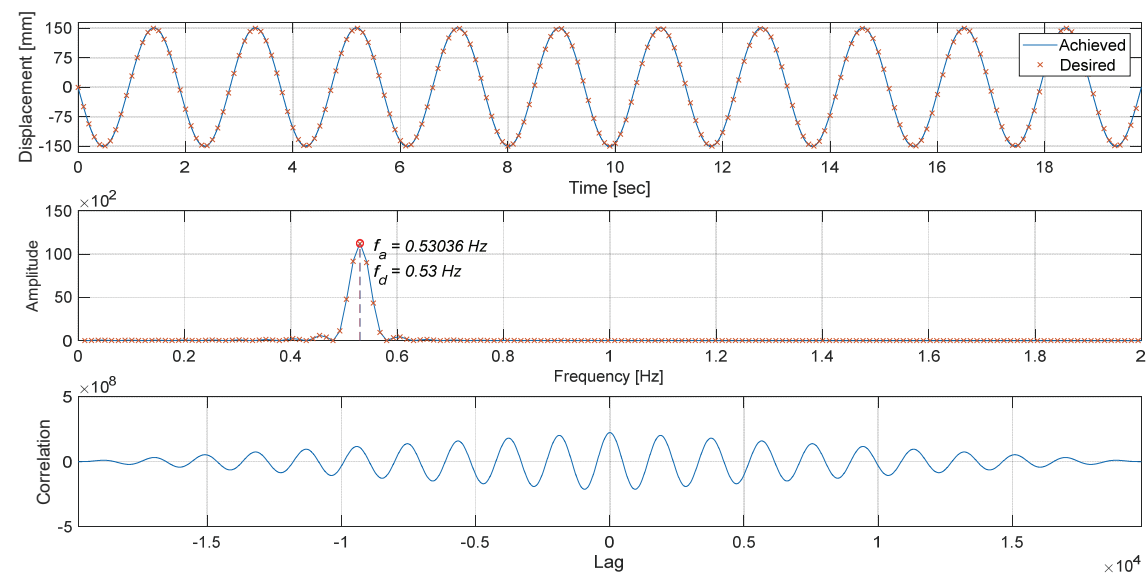

Figure 5 - Results after calibration for $150 \mathrm{~mm}$ amplitude at $0.53 \mathrm{~Hz}$ under $600 \mathrm{~kg}$ lumped mass 

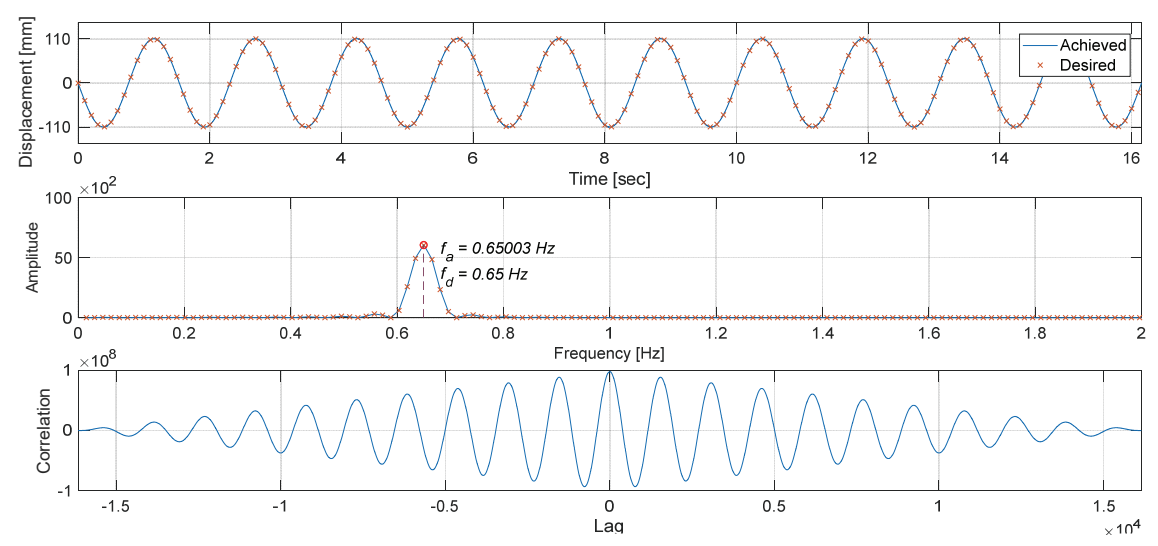

Figure 6 - Results after calibration for $110 \mathrm{~mm}$ amplitude at $0.65 \mathrm{~Hz}$ under $600 \mathrm{~kg}$ lumped mass

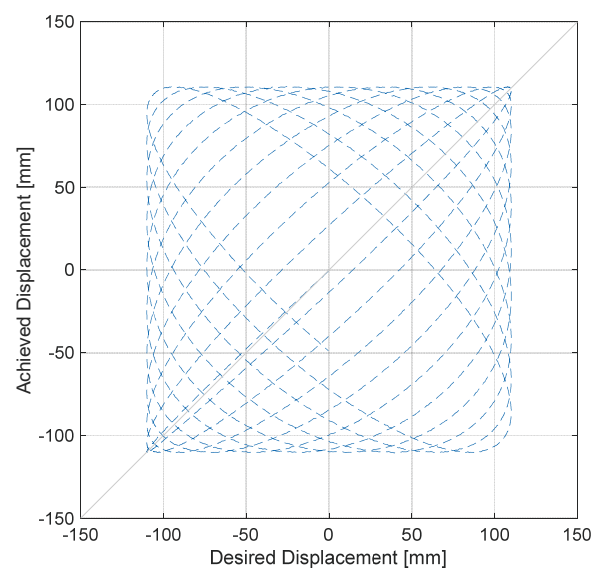

(a)

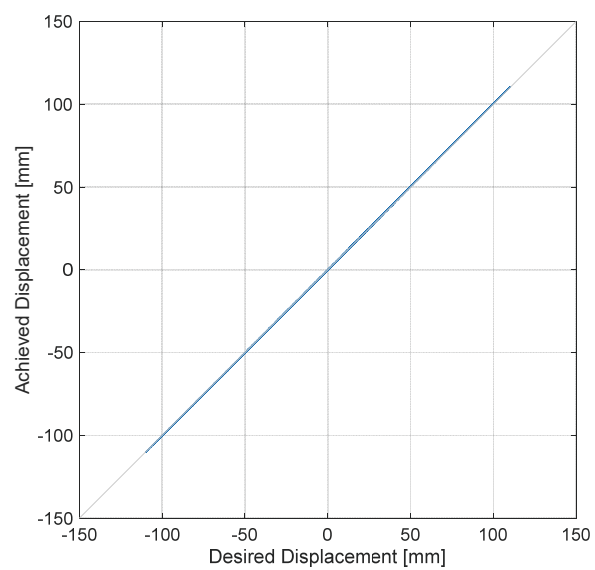

(b)

Figure 7 - Synchronization subspace plots (SSP) for $110 \mathrm{~mm}$ amplitude at $0.65 \mathrm{~Hz}$ under $600 \mathrm{~kg}$ lumped mass: (a) Un-calibrated ( $\left.\varepsilon_{\text {rel }}=128.05 \%\right)$, (b) Calibrated $\left(\varepsilon_{\text {rel }}=0.52 \%\right)$.

\subsection{Use of Calibration in Earthquake Simulation}

As a result of the calibration process performed under harmonic motion providing sufficient accuracy, an average delay value was chosen by considering these calibration values in earthquake simulation because of the variable frequency content of the earthquake. As can be seen in Tables 2 and 3, latencies vary between 6-9 $\mu \mathrm{s}$. In this study, the latency value for earthquake simulations was selected as $8 \mu \mathrm{s}$. In this case, the simulated ground motion was compared with scaled ground motion as a result of simultaneous measurements taken from both axes via linear potentiometers. From the PEER strong ground motion database [15], the 
1999 Chi-Chi earthquake was selected for simulation, and the test was carried out under 240 $\mathrm{kg}$ payload for the latency value of $8 \mu \mathrm{s}$. In Figures 8 and 9, the plotted graphs of the desired and achieved motions of the $x$ and $y$ components of the $1 / 3$ scale Chi-Chi earthquake and their cross-correlation are given. Displacement records taken in 1/3 scale Chi-Chi Earthquake simulation are evaluated using the relative RMS error, $\varepsilon_{r e l}$ with Eq. (2). The errors calculated between the desired $\left(x_{d}\right)$ and the measured $\left(x_{a}\right)$ displacements are $\varepsilon_{r e l}=4.05 \%$ for the $x$-axis and $\varepsilon_{r e l}=3.41 \%$ for the $y$-axis. The error was seen to be less than $5 \%$ and found to be within the acceptable range. This approach's accuracy is also shown in Figure 10 by SSP graphs, where the relationship between the desired vs. achieved earthquake motion is nearly overlapped on the $45^{\circ}$ reference line, indicating minimum delays.

$$
\varepsilon_{r e l}=\frac{\sqrt{(1 / N) \sum_{n=1}^{N}\left(x_{a}[n]-x_{d}[n]\right)^{2}}}{\sqrt{(1 / N) \sum_{n=1}^{N}\left(x_{d}[n]\right)^{2}}} \times 100
$$

As a further example, simulations were performed for the 1999 Düzce earthquake on both the bare and loaded shake table. Figures 11 and 12 show the comparison between the desired and measured displacement records for the $x$-axis and the $y$-axis, respectively. Using Eq. (2), relative RMS error was calculated as $\varepsilon_{r e l}=3.30 \%$ for the $x$-axis and $\varepsilon_{r e l}=3.31 \%$ for the $y$-axis. Figure 13 shows that the relationship between the desired and achieved earthquake motion is of sufficient accuracy with SSP graphics. During this simulation, accelerations were recorded by the aid of a low-cost 3-axis acceleration sensor (MPU6050) mounted on the table. Comparative graphs of the acceleration recordings, the FFT spectrums, and acceleration response spectra obtained from the desired and measured acceleration data are given in Figures 14 and 15 for the $x$ and $y$-axis, respectively. The $4^{\text {th }}$ degree Butterworth low pass filter was applied to the acceleration recordings where the upper cut-off frequency was set to $21 \mathrm{~Hz}$. The damping rate was taken as $5 \%$ for the acceleration response spectrum graph. By using Equation (3) for the desired $\left(\ddot{x}_{d}\right)$ and achieved ( $\left.\ddot{x}_{a}\right)$ acceleration records, relative RMS errors are calculated as $\varepsilon_{r e l}=21.84 \%$ for the $x$-axis and $\varepsilon_{r e l}=31.96 \%$ for the $y$-axis. It was seen that the results obtained from the acceleration records coincide with the characteristic of the desired acceleration record.

$$
\varepsilon_{r e l}=\frac{\sqrt{(1 / N) \sum_{n=1}^{N}\left(\ddot{x}_{a}[n]-\ddot{x}_{d}[n]\right)^{2}}}{\sqrt{(1 / N) \sum_{n=1}^{N}\left(\ddot{x}_{d}[n]\right)^{2}}} \times 100
$$

Another example of the experiments performed on the loaded shake table after the experiments on the bare table is the $1 / 15$ scale 1999 Düzce earthquake. It was estimated that the desired strong ground motion could be performed on both axes under $360 \mathrm{~kg}$ payloads for this scale, with the methodology given by Damcı and Şekerci [13]. Figure 16 and Figure 17 show the comparison of the displacement records taken for the $x$ and $y$ axes, respectively. As a result of the calculations carried out for the desired $\left(x_{d}\right)$ and achieved $\left(x_{a}\right)$ displacement records, using Eq. (2), the relative RMS errors obtained on both axes were $\varepsilon_{\text {rel }}=2.06 \%$ for the $x$-axis and $\varepsilon_{r e l}=5.64 \%$ for the $y$-axis. Figure 18 shows that the relationship between the desired and achieved earthquake motion is of sufficient accuracy with SSP graphics. 

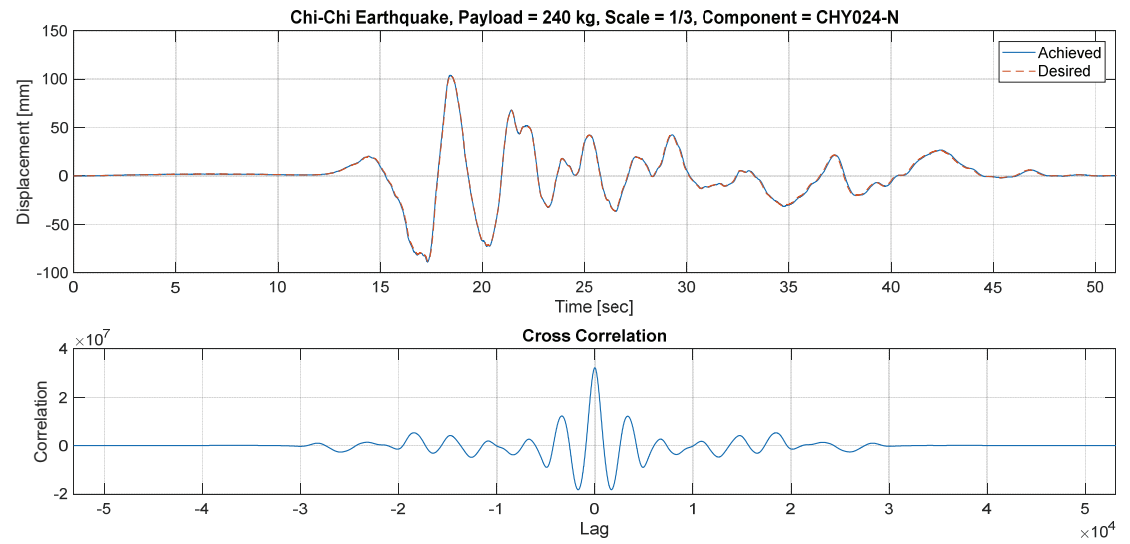

Figure 8 - Comparison of desired and achieved strong ground motion simulation at $x$-axis for 1/3 scale Chi-Chi earthquake under $240 \mathrm{~kg}$ payload
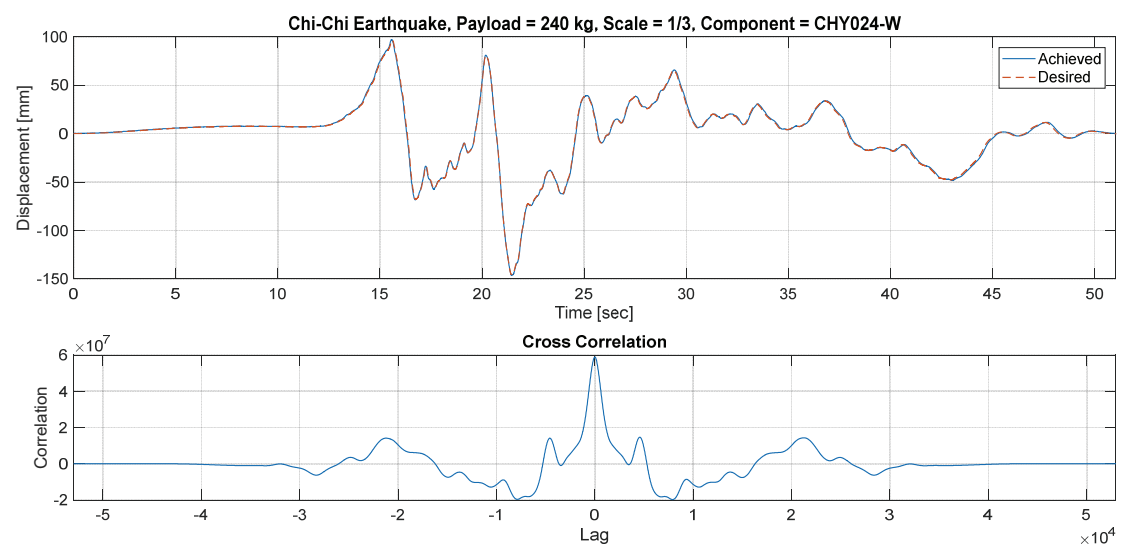

Figure 9 - Comparison of desired and achieved strong ground motion simulation at y-axis for 1/3 scale Chi-Chi earthquake under $240 \mathrm{~kg}$ payload

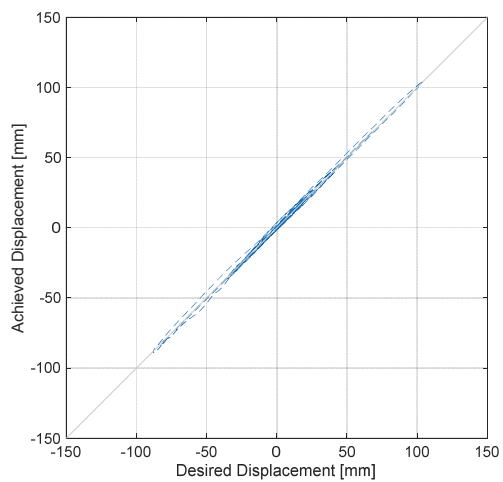

(a)

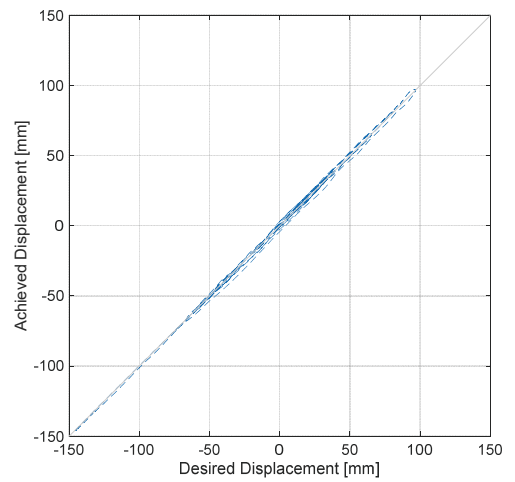

(b)

Figure 10 - Synchronization subspace plots (SSP) for 1/3 scale Chi-Chi earthquake: (a) $x$-axis $\left(\varepsilon_{\text {rel }}=4.05 \%\right)$, (b) y-axis $\left(\varepsilon_{\text {rel }}=3.41 \%\right)$. 

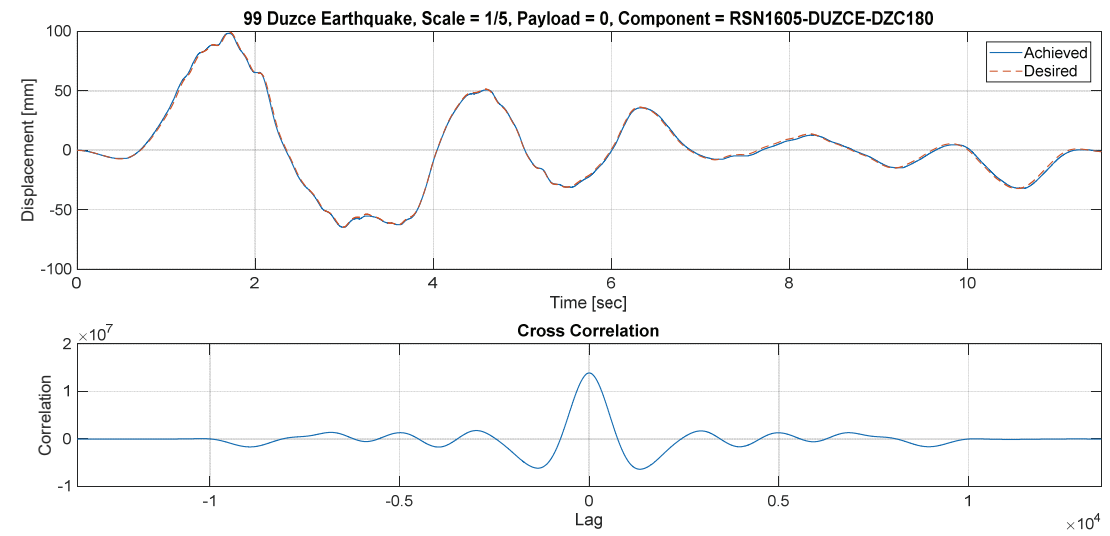

Figure 11 - Comparison of desired and achieved strong ground motion simulation at $x$-axis for 1/5 scale Düzce earthquake for the bare table (payload=0)
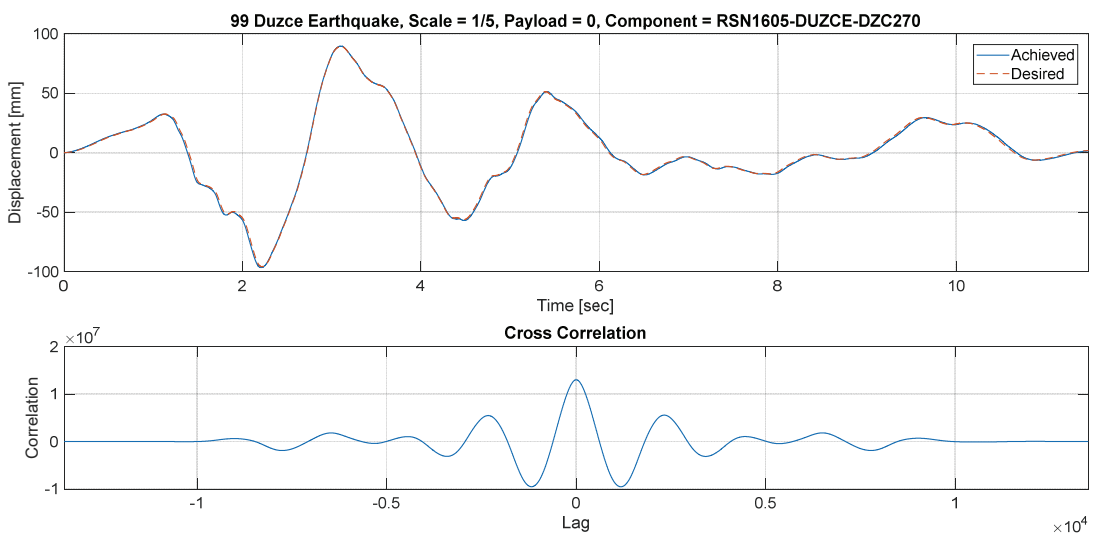

Figure 12 - Comparison of desired and achieved strong ground motion simulation at y-axis for 1/5 scale Düzce earthquake for the bare table (payload=0)

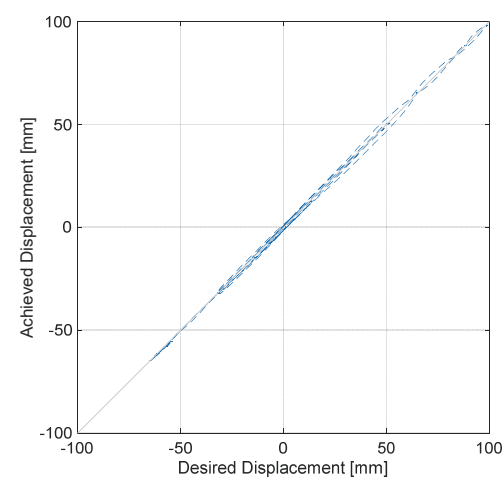

(a)

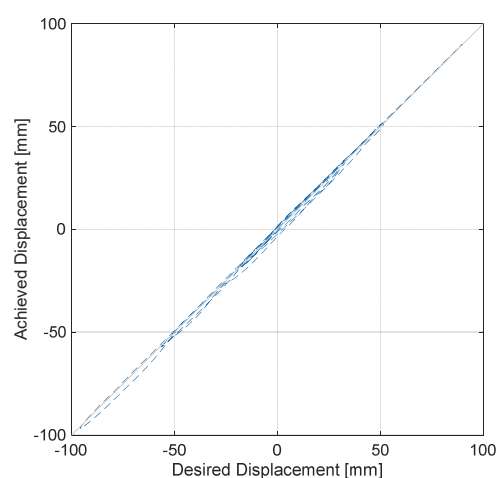

(b)

Figure 13 - Synchronization subspace plots (SSP) for 1/5 scale Düzce earthquake: (a) $x$-axis $\left(\varepsilon_{\text {rel }}=3.30 \%\right)$, (b) y-axis $\left(\varepsilon_{r e l}=3.31 \%\right)$. 

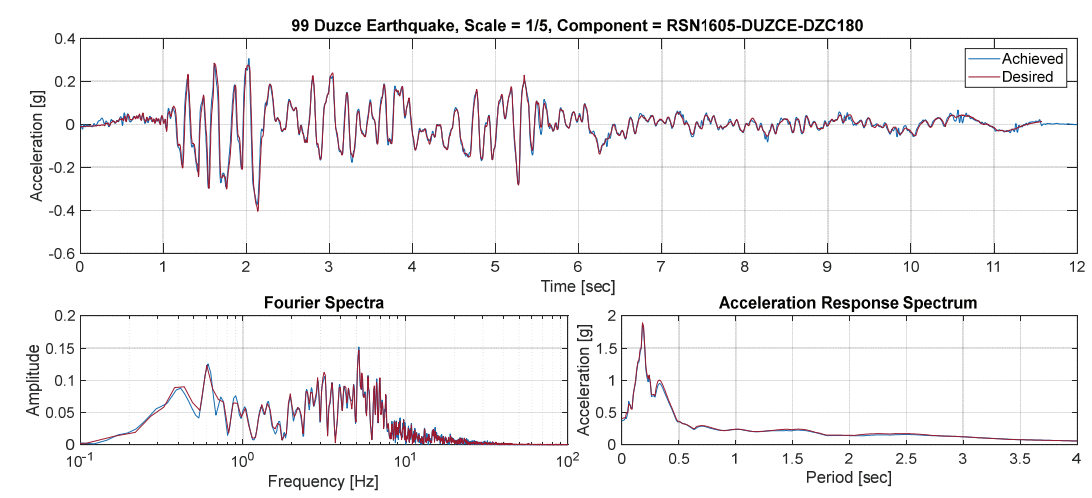

Figure 14 - Comparison of desired and achieved accelerations of 1/5 scale Düzce earthquake simulation at the $x$-axis, their frequency content and acceleration response spectra for the bare table
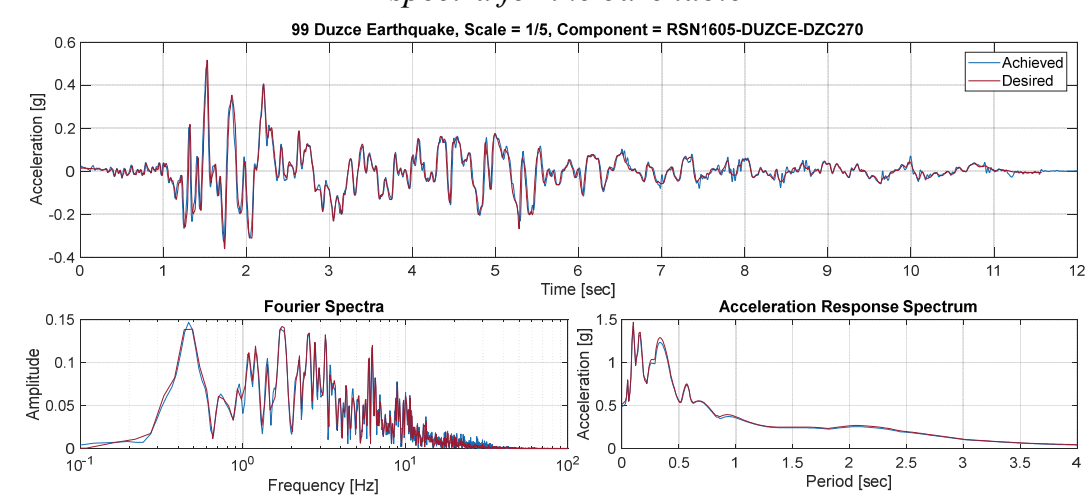

Figure 15 - Comparison of desired and achieved accelerations of 1/5 scale Düzce earthquake simulation at the y-axis, their frequency content and acceleration response spectra for the bare table
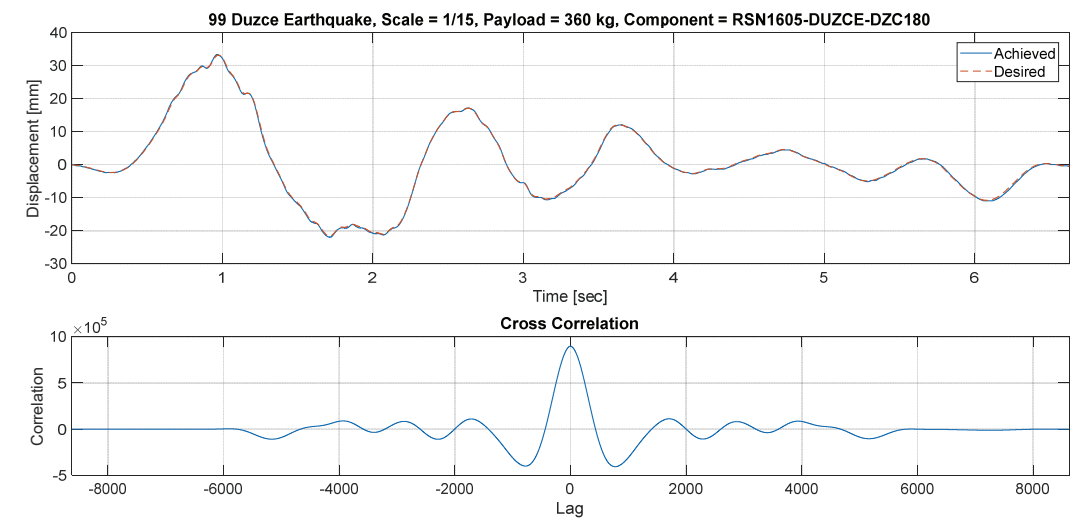

Figure 16 - Comparison of desired and achieved strong ground motion simulation at $x$-axis for 1/15 scale Düzce earthquake for $360 \mathrm{~kg}$ payload 

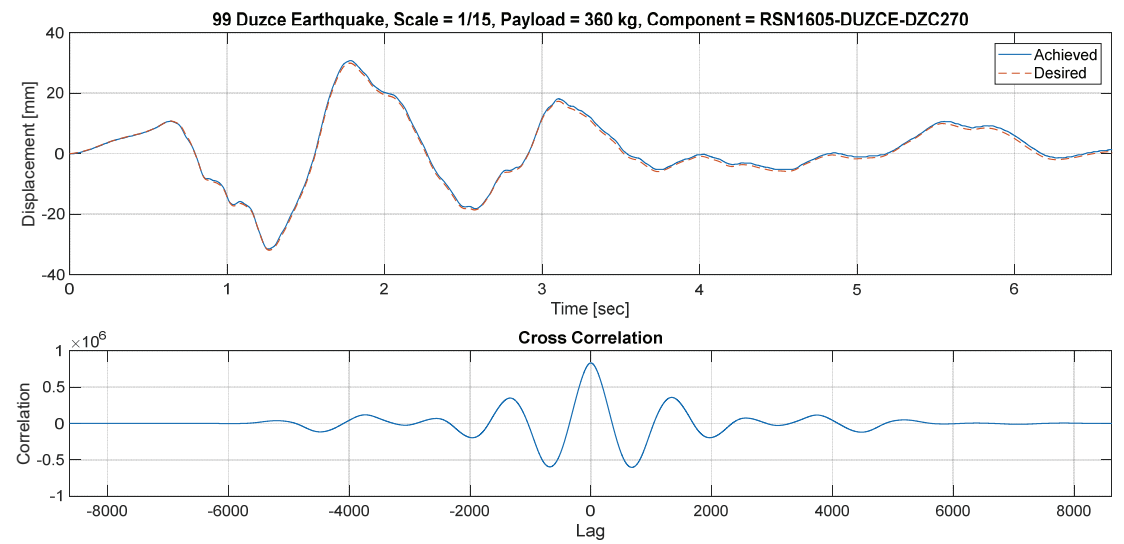

Figure 17 - Comparison of desired and achieved strong ground motion simulation at y-axis for 1/15 scale Düzce earthquake for $360 \mathrm{~kg}$ payload

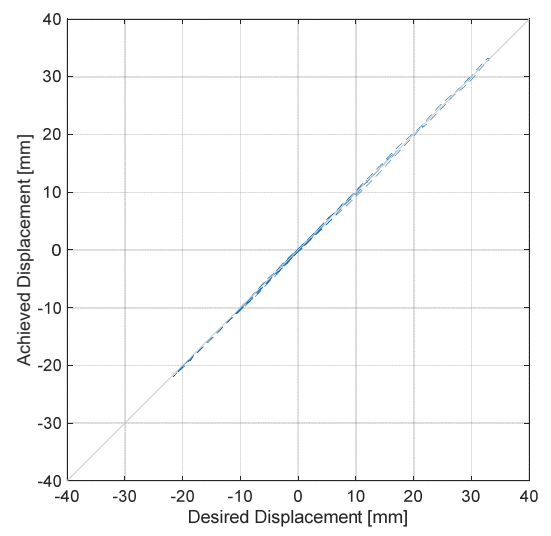

(a)

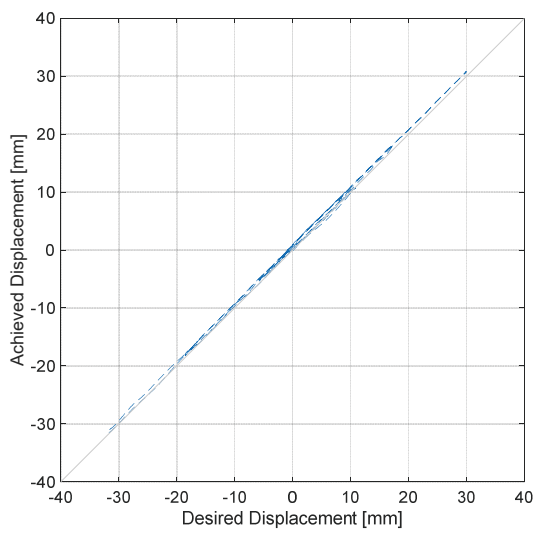

(b)

Figure 18 - Synchronization subspace plots (SSP) for 1/15 scale Düzce earthquake: (a) $x$-axis $\left(\varepsilon_{r e l}=2.06 \%\right)$, (b) y-axis $\left(\varepsilon_{r e l}=5.64 \%\right)$.

\section{CONCLUSIONS}

In the experiments to be performed with the shake table developed in this study, a technique for calibrating the table is presented to determine the table performance accurately and perform the simulations with minimum errors. For this purpose, $350 \mathrm{~mm}$ linear potentiometric rulers placed between the table plates were used, and the table was calibrated using displacement records taken from these rulers. Due to the 10-bit ADC resolution of the Arduino MEGA development board, which forms the data acquisition unit, the sensitivity of reading signals from the linear potentiometer is $0.342 \mathrm{~mm}$. This resolution is insufficient for tracking small-amplitude harmonic motions but provides sufficient resolution for the table's maximum displacement capacity of $\pm 150 \mathrm{~mm}$. In order to drive the shake table accurately 
for the desired motion information, many measurements were taken by frequency scanning for different harmonic motion simulations, and calibration tables were obtained from the experimental results for $x$ and $y$ axes. The corrections were made with the help of software developed by open-loop control technique using these results. Besides, the effect of calibration on bi-axial earthquake simulation was examined, and it was found that the presented calibration technique was able to simulate the desired strong ground motion with a relative RMS error of about 5\%, under repeated trials. With these satisfactory results, the shake table SARSAR can be used for future research projects to investigate structural behavior under simulated bi-axial earthquake excitations.

\section{Symbols}

A Amplitude of the harmonic motion

$f_{a} \quad$ Achieved (response) frequency

$f_{d} \quad$ Desired (demand) frequency

$l_{t} c_{f} \quad$ Latency per step

$N \quad$ Number of samples

$x_{a} \quad$ Achieved (measured) displacement

$x_{d} \quad$ Desired displacement

$\ddot{x}_{a} \quad$ Achieved (measured) acceleration

$\ddot{x}_{d} \quad$ Desired acceleration

$\Delta s \quad$ Unit displacement of the actuator assembly for a single step

$\varepsilon_{\text {rel }} \quad$ Relative root mean square error

\section{Acknowledgment}

This study was supported by the TUBITAK 3001- Starting R\&D Projects Funding Program with project number $216 \mathrm{M} 075$. The authors gratefully thank TÜBİTAK, who provided the project support and project supervisor Prof. Dr. Cenk ALHAN.

\section{References}

[1] O. Ozcelik, J.E. Luco, J.P. Conte, Identification of the mechanical subsystem of the NEES-UCSD shake table by a least-squares approach, Journal of Engineering Mechanics, 134(2008)23-34. $\quad$ https://doi.org/10.1061/(ASCE)07339399(2008)134:1(23)

[2] S.E. Kim, D.H. Lee, C. Ngo-Huu, Shaking table tests of a two story unbraced steel frame. Journal of Constructional Steel Research, 63 (2007) 412-421. https://doi.org/10.1016/j.jcsr.2006.04.009 
[3] J. Kuehn, D. Epp, W. N. Patten, High-fidelity control of a seismic shake table, Earthquake Engineering and Structural Dynamics, 28 (1999) 1235-1254. https://doi.org/10.1002/(SICI)1096-9845(199911)28:11<1235::AIDEQE864>3.0.CO;2-H

[4] N. Nakata, Acceleration trajectory tracking control for earthquake simulators, Engineering Structures, 32 (2010) 2229-2236. https://doi.org/10.1016/j.engstruct. 2010.03.025

[5] J. E. Luco, O. Ozcelik, J. P. Conte, Acceleration Tracking Performance of the UCSDNEES Shake Table. Journal of Structural Engineering, 136 (2010) 481-490. https://doi.org/10.1061/(ASCE)ST.1943-541X.0000137

[6] T. Y. Yang, K. Li, J. Y. Lin, Y. Li, D. P. Tung, Development of high-performance shake tables using the hierarchical control strategy and nonlinear control techniques, Earthquake Engineering \& Structural Dynamics, 44 (2015) 1717-1728. https://doi.org/10.1002/eqe.2551

[7] M. Saranik, D. Lenoir, L. Jézéquel, Shaking table test and numerical damage behaviour analysis of a steel portal frame with bolted connections, Computers and Structures, 112-113 (2012) 327-341. https://doi.org/10.1016/j.compstruc.2012.07.009

[8] R. Zhang, P. V. Lauenstein, B. M. Phillips, Real-time hybrid simulation of a shear building with a uni-axial shake table, Engineering Structures, 119 (2016) 217-229. https://doi.org/10.1016/j.engstruct.2016.04.022.

[9] A. C. Altunisik, A. Yetisken, V. Kahya, Experimental study on control performance of tuned liquid column dampers considering different excitation directions, Mechanical Systems and Signal Processing, 102 (2018) 59-71. https://doi.org/10.1016/j.ymssp. 2017.09.021

[10] Z. Fırat Alemdar, Betonarme Köprü Kolonlarında Plastik Mafsal Bölgelerinin Modellenmesi, IMO Teknik Dergi, 444 (2015) 7279-7286.

[11] A. Ashasi-Sorkhabi, H. Malekghasemi, O. Mercan, Implementation and verification of real-time hybrid simulation (RTHS) using a shake table for research and education, Journal of Vibration and Control, 21(8) (2015) 1459-1472. DOI: $10.1177 / 1077546313498616$

[12] A. Najafi, B. F. Spencer Jr, Modified model-based control of shake tables for online acceleration tracking, Earthquake Engng Struct Dyn., (2020) 1-17. DOI: 10.1002/eqe. 3326

[13] E. Damc1, Ç. Şekerci, Development of a Low-Cost Single-Axis Shake Table Based on Arduino. Experimental Techniques, $43 \quad$ (2019) 179-198. https://doi.org/10.1007/s40799-018-0287-5

[14] MATLAB version R2017b, 2017, computer program, The MathWorks Inc., Natick, Massachusetts.

[15] PEER Ground Motion Database - PEER Center. http://ngawest2.berkeley.edu/ (Accessed, 15 ${ }^{\text {th }}$ November 2018). 